\title{
(1) Coperal Medicine \\ TENOFOVIR ASSOCIATED RENAL TOXICITY IN A COHORT OF HIV INFECTED INDIVIDUALS IN GOA
}

\begin{tabular}{|c|c|}
\hline $\begin{array}{l}\text { Dr. Hardik P } \\
\text { Patel* }\end{array}$ & $\begin{array}{l}\text { Department Of Medicine, Goa Medical College, Bambolim Goa, India } \\
\text { *Corresponding Author }\end{array}$ \\
\hline $\begin{array}{l}\text { Dr. Shubham } \\
\text { Kumar }\end{array}$ & Department Of Medicine, Goa Medical College, Bambolim Goa, India \\
\hline $\begin{array}{l}\text { Dr. Deepashree } \\
\text { Talaulikar }\end{array}$ & $\begin{array}{l}\text { Department Of Preventive And Social Medicine, Goa Medical College, Bambolim } \\
\text { Goa, India }\end{array}$ \\
\hline \multicolumn{2}{|c|}{$\begin{array}{l}\text { ABSTRACT OBJECTIVE: Tenofovir disoproxil fumarate (TDF) is a nucleotide analogue recommended in international HIV } \\
\text { treatment guidelines. Purpose of this study was to stimate the long term effects of TDF on renal profile in a cohort of HIV } \\
\text { patients in Goa. Three hundred and fifty four ( } 354 \text { ) consecutive HIV-positive patients who initiated TDF-based antiretroviral treatment from Jan } \\
2016 \text { to Dec } 2018 \text { at the Goa Medical College were sampled. Creatinine clearance (CrCl) was calculated using the Cockcroft-Gault equation at } \\
\text { baseline and renal impairment was defined as CrCl values of } 30.0-49.9 \mathrm{~mL} / \mathrm{min} \text { (moderate renal impairment) and }<25 \mathrm{~mL} / \mathrm{min} \text { (severe renal } \\
\text { impairment) as per institutional guidelines for renal function test. } \\
\text { RESULTS: Follow up time was } 2 \text { years. Atstudy endpoint, } 36 \text { participants }(10.2 \%) \text { recorded CrCl rate below } 50 \mathrm{~mL} / \text { min indicating incident renal } \\
\text { impairment, made up of } 8.47 \% \text { moderate renal impairment and } 1.7 \% \text { severe renal impairment. Factors associated with incidence of renal } \\
\text { impairment were increasing age, WHO HIV stage III/IV and baseline low CD4 count. Patients with identified renal impairment risk factors at } \\
\text { ART initiation should be targeted and monitored effectively to prevent renal injury. }\end{array}$} \\
\hline
\end{tabular}

KEYWORDS : Tenofovir Disoproxil Fumarate, Renal Dysfunction, Creatinine Clearance, Hiv, Art

\section{INTRODUCTION:}

HIV infection/AIDS is a global pandemic with 37.9 million individual living with HIV at the end of 2018 as per UNAIDS/WHO. An estimate of 36.2 million adults with 1.7 million being children affected below the age of 15 years.

The estimated number of people living with HIV- i.e., the global prevalence -has increased more than four fold since 1990, reflecting the combined effects of continued high rates of new HIV infection and the life prolonging impact of anti-retro viral therapy. These ARVs are expected to be taken throughout the patient's life time once the decision to initiate ART is made. ARVs have documented side effects and adverse drug reactions ranging from mild to life threatening ones with their effect being transient or prolonged.

Tenofovir disoproxil fumarate is an orally bio-available prodrug of tenofovir, an acyclic nucleotide analogue reverse-transcriptase inhibitor (NtRTI), widely used in the treatment of HIV infection and also approved for treatment of Hepatitis B virus infection widely. Tenofovir is preferred in most consolidated ART guidelines in preference to the use of stavudine and zidovudine because of better tolerance, low frequency of adverse events and a once daily dosing combination of tenofovir, lamivudine or emtricitabine and efavirenz[1]. Concerns regarding nephrotoxicity were initially raised by the structural similarity between tenofovir and the Nephrotoxic acyclic nucleotide analogues adefovir and cidofovir.[2] Although the incidence of TDF-related kidney dysfunction seems to be low in most settings, the effect of TDF on renal profile in patients starting ART with varying levels of renal function has not been studied previously in our setting. It is against this background that this research was undertaken to study changes in renal function over time in patients on tenofovir based antiretroviral regimen in our patient population at a tertiary hospital in Goa at Goa medical college. We investigated the incidence of renal impairment in HIV positive patients treated with TDF based regimen and identified associated risk factors.

\section{MATERIALS AND METHODS:}

- The population for this study consisted of HIV positive patients captured in the database at ART centre at tertiary care centre Goa medical college.

- The study was limited to patients initiated on tenofovir-based regimen within the study period.

- This is retrospective cohort study of consecutive patients (with baseline creatinine clearance rate of $\geq 50 \mathrm{~mL} / \mathrm{min}$ ) who started tenofovir based regimen from January 2016 with study endpoint at

\section{December 2018}

- A clinical research form was used to collect data from patients folders.

- Data of primary interest were demographics, serum creatinine and urea at baseline, weight, tenofovir based regimens, HIV serotyping and CD4 count at baseline.

- Other information of secondary interest included were comorbidities and co-medications.

- Patients were followed up from the study start point of January 2016 until renal impairment, death, or 31st December 2018, whichever came first.

- Absolute change in creatinine clearance $(\mathrm{CrCl})$ using the Cockcroft-Gault equation was calculated at baseline and as per institutional guidelines for renal function test.

- Renal impairment was defined as a reduction in $\mathrm{CrCl}$ below 50 $\mathrm{mL} / \mathrm{min}$ (moderate renal impairment) and below $25 \mathrm{~mL} / \mathrm{min}$ (severe renal impairment).

- Descriptive and univariate analysis were conducted for demographic, clinical and laboratory characteristics established for the study.

- Patient's demography was described using mean \pm standard deviation (SD) for continuous variables and percentages for categorical data.

Written informed consent from each study participant was not obtained as the study was retrospective and involved using intuitional database. However data, name, details obtained was kept confidential and approval for this waiver in addition to approval for the entire study protocol was obtained from the Ethics Committee of the Institution.

\section{INCLUSION CRITERIA:}

- HIV positive individuals on Anti retro viral therapy containing Tenofovir.

- Good compliance to treatment $(>80 \%)$

EXCLUSION CRITERIA:

- Individual on ART not containing Tenofovir

- Poor compliance to therapy $(<80 \%)$

- Patients failed to follow up after $1^{\text {st }}$ registration

DATAVARIABLES:

Age

Gender (male/female)

Weight

Smoke use (yes/no) 
Volume-10 | Issue-1 | January - 2020 | PRINT ISSN No. 2249 - 555X | DOI : 10.36106/ijar

Alcohol (yes /no)

WHO HIV stage (I/II/III/IV)

HIV type (type I / type II)

ART regimen administered (PI based/ NNRTI based)

Baseline CD4 count (cells $\left./ \mathrm{mm}^{3}\right)(<150 / 150-250 />250)$

Presence of co-morbility( DM/HTN/IHD)

Baseline Creatinine ( $>50 \mathrm{ml} / \mathrm{min})$

Creatinine at End point $(>50 \mathrm{ml} / \mathrm{min} / 25-50 /<25 \mathrm{ml} / \mathrm{min})$

\section{TABLES:}

Table No 1 : Characteristics of Patient taking Tenofovir containing regimen in ART center of Goa Medical College

\begin{tabular}{|c|c|}
\hline Characteristics & $\mathrm{N}(\%)$ \\
\hline \multicolumn{2}{|l|}{ AGE } \\
\hline $10-19$ & $20(5.6 \%)$ \\
\hline $20-29$ & $58(16.4 \%)$ \\
\hline $30-39$ & $106(29.9 \%)$ \\
\hline $40-49$ & $118(33.3 \%)$ \\
\hline $50-59$ & $38(10.7 \%)$ \\
\hline $60-70$ & $14(4.0 \%)$ \\
\hline \multicolumn{2}{|c|}{ BASELINE BODY WEIGHT(KG) } \\
\hline $10-30$ & $6(1.7 \%)$ \\
\hline $30-50$ & $172(48.6 \%)$ \\
\hline $50-70$ & $150(42.4 \%)$ \\
\hline $70-90$ & $26 .(7.3 \%)$ \\
\hline \multicolumn{2}{|l|}{ SEX } \\
\hline Male & $181(51.1 \%)$ \\
\hline Female & $173(48.9 \%)$ \\
\hline \multicolumn{2}{|c|}{ ALCOHOL CONSUMPTION } \\
\hline Yes & $90(25.4 \%)$ \\
\hline No & $264(74.6 \%)$ \\
\hline \multicolumn{2}{|l|}{ SMOKING } \\
\hline Yes & $101(28.5 \%)$ \\
\hline No & $253(71.5 \%)$ \\
\hline \multicolumn{2}{|c|}{ WHO CLINICAL STAGGING } \\
\hline WHO Stage I & $2(0.6 \%)$ \\
\hline WHO Stage II & $186(52.5 \%)$ \\
\hline WHO Stage III & $22(6.2 \%)$ \\
\hline WHO Stage IV & $144(40.7 \%)$ \\
\hline \multicolumn{2}{|c|}{ BASELINE CD4 COUNT } \\
\hline$<150$ & $96(27.1 \%)$ \\
\hline $150-250$ & $59(16.7 \%)$ \\
\hline$>250$ & $199(56.2 \%)$ \\
\hline \multicolumn{2}{|l|}{ HIV TYPE } \\
\hline HIV Type 1 & $352(99.4 \%)$ \\
\hline HIV Type 2 & $2(0.6 \%)$ \\
\hline \multicolumn{2}{|l|}{ ART REGIMEN } \\
\hline TLE & $351(99.2 \%)$ \\
\hline TL/LPVR & $3(0.8 \%)$ \\
\hline \multicolumn{2}{|l|}{ COMORBIDITIES } \\
\hline Yes & $41(11.6 \%)$ \\
\hline No & $313(88.4 \%)$ \\
\hline \multicolumn{2}{|c|}{ RENAL IMPAIREMENT } \\
\hline Impairment present & $36(10.2 \%)$ \\
\hline No impairment & $318(89.8 \%)$ \\
\hline Total & $354(100.0 \%)$ \\
\hline
\end{tabular}

Graph 1: Baseline Creatinine clearance of at the time of initiation tenofovir containing regimen to the patient attending ARTC of Goa Medical College

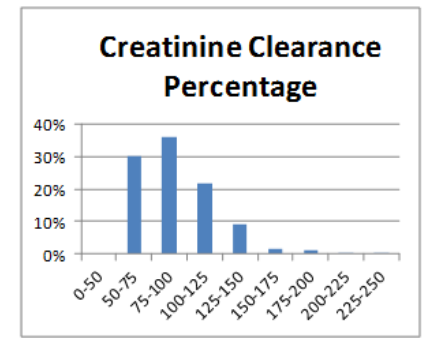

Graph 2: Creatinine clearance after starting tenofovir containing regimen to the patient attending ARTC of Goa Medical College

\section{percentage of creatinine clearance \\ after starting tenofovir conting regimen}

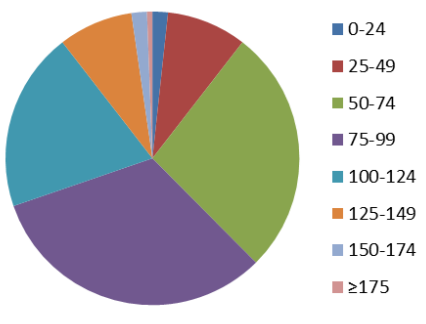

Table No 2: Association of baseline Cd4 count, age, sex, baseline WHO grading, alcohol consumption, smoking, comorbidities of patient on tenofovir containing regimen with renal impairment

\begin{tabular}{|c|c|c|c|c|}
\hline & \multicolumn{2}{|c|}{ RENAL IMPAIRMENT } & \multirow[t]{2}{*}{ Total } & \multirow[t]{2}{*}{ P value } \\
\hline CD4 COUNT & Yes & No & & \\
\hline$<150$ & $19(19.8 \%)$ & $77(80.2 \%)$ & $96(100 \%)$ & \\
\hline $150-250$ & $8(13.6 \%)$ & $51(86.4 \%)$ & $59(100 \%)$ & \\
\hline$>250$ & $9(4.5 \%)$ & $190(95.5 \%)$ & $199(100 \%)$ & \\
\hline Total & $36(10.2 \%)$ & $318(89.8 \%)$ & $354(100 \%)$ & 0.00 \\
\hline $\begin{array}{c}\text { AGE } \\
\text { ( in years) }\end{array}$ & Yes & No & & \\
\hline $10-19$ & $1(5.0 \%)$ & $19(95.0 \%)$ & $20(100 \%)$ & \\
\hline $20-29$ & $3(5.2 \%)$ & $55(94.8 \%)$ & $58(100 \%)$ & \\
\hline $30-39$ & $2(1.9 \%)$ & $104(98.1 \%)$ & $106(100 \%)$ & \\
\hline $40-49$ & $19(16.1 \%)$ & $99(83.9 \%)$ & $118(100 \%)$ & \\
\hline $50-59$ & $8(21.1 \%)$ & $30(78.9 \%)$ & $38(100 \%)$ & \\
\hline $60-70$ & $3(21.4 \%)$ & $11(78.6 \%)$ & $14(100 \%)$ & \\
\hline Total & $36(10.2 \%)$ & $318(89.8 \%)$ & $354(100 \%)$ & 0.001 \\
\hline SEX & Yes & No & & \\
\hline Male & $15(8.3 \%)$ & $166(91.7 \%)$ & $188(100 \%)$ & \\
\hline Female & $21(12.1 \%)$ & $152(87.9 \%)$ & $173(100 \%)$ & \\
\hline Total & $36(10.2 \%)$ & $318(89.8 \%)$ & $354(100 \%)$ & 0.231 \\
\hline $\begin{array}{c}\text { BASELINE } \\
\text { WHO GRADING }\end{array}$ & Yes & No & & \\
\hline Stage $1+2$ & $11(5.9 \%)$ & $177(94.1 \%)$ & $188(100 \%)$ & \\
\hline Stage $3+4$ & $25(15.1 \%)$ & $141(84.9 \%)$ & $166(100 \%)$ & \\
\hline Total & $36(10.2 \%)$ & $318(89.8 \%)$ & $354(100 \%)$ & 0.04 \\
\hline $\begin{array}{c}\text { ALCOHOL } \\
\text { CONSUMPTION }\end{array}$ & Yes & No & & \\
\hline Yes & $9(10.0 \%)$ & $81(90.0 \%)$ & $90(100 \%)$ & \\
\hline No & $27(10.2 \%)$ & $237(89.8 \%)$ & $264(100 \%)$ & \\
\hline Total & $36(10.2 \%)$ & $318(89.8 \%)$ & $354(100 \%)$ & 0.951 \\
\hline SMOKING & Yes & No & & \\
\hline Yes & $8(7.9 \%)$ & $93(92.1 \%)$ & $101(100 \%)$ & \\
\hline No & $28(11.1 \%)$ & $225(88.9 \%)$ & $253(100 \%)$ & \\
\hline Total & $36(10.2 \%)$ & $318(89.8 \%)$ & $354(100 \%)$ & 0.376 \\
\hline COMORBIDITIES & Yes & No & & \\
\hline Yes & $7(17.1 \%)$ & $34(82.9 \%)$ & $41(100 \%)$ & \\
\hline No & $29(9.3 \%)$ & $284(90,4 \%)$ & $313(100 \%)$ & \\
\hline Total & $36(10.2 \%)$ & $318(89.8 \%)$ & $354(100 \%)$ & 0.120 \\
\hline
\end{tabular}

\section{DISCUSSION:}

We found that approximately 1 out of 10 patients on tenofovir based regimen from Goa, India at Goa Medical College experienced development of renal impairment over the 2 years period of this study. It is worth noting that of these about $11.8 \%$ developed mild renal impairment. Factors associated with the incidence of renal impairment were older age, baseline CD4, WHO HIV stages III and IV. The Incidence of renal impairment after initiation of TDF based regimens is varied across studies [3-6], but tended to be lower than the 
incidences observed in this study. This could be due to different study method approaches used and/or varying renal impairment incidences in different populations. However, a Japanese retrospective study of 493 patients initiated on TDF based regimen reported similar incidence of declining renal function [7], comparable with this study. The clinical implication is not certain but it is proven that patients on tenofovir based regimen tend to develop decreases in renal performance as compared to those on non-tenofovir based regimens [8]. Although findings from this study indicate no association between type of TDF regimen administered (TDF-based regimen with protease inhibitors lopinavir/ritonavir or TDF-based regimen with nonnucleoside inhibitors efavirenz or nevirapine) and renal impairment, other studies reported that the degree of renal function decline was more frequent and more serious in TDF-based regimen with protease inhibitors lopinavir/ritonavir than TDF-based regimen with nonnucleoside inhibitors (efavirenz or nevirapine) $[10,11]$. The number of patients on TDF-based protease inhibitor regimen in our study was however very low and therefore could account for the lack of association between type of TDF-based regimen and renal impairment. Forty six percent $(46 \%)$ of participants were found to have WHO Stage III and IV disease and this was found to be associated with declining renal performance. Literature supports this finding as worsening HIV disease results in various opportunistic infections that worsen kidney performance [12]. Older age was established to be associated with renal impairment in our study analysis and this is consistent with other studies which associated older age with low baseline $\mathrm{CrCl}[9,10,12]$.

\section{CONCLUSON:}

The use of TDF based regimen as first line ART regimen in Goa based on its beneficial attributes. However, the incidence of renal impairment of 1 in every 10 patients with $1.7 \%$ developing severe renal impairment on TDF-based ART as determined in this study supports the argument of requesting for laboratory support for serial monitoring of serum creatinine.

\section{LIMITATION:}

The unavailability of creatinine and urea recordings regularly is considered a limitation to this study. We had to use available recordings as and when available in the medical folders and the database.

Many patients failed to follow up after $1^{\text {st }}$ visit to ART centre and their subsequent creatinine were unavailable.

The small sample size limited us in assessing the association between the various TDF-based regimen types and renal impairment and also conduct a multiple regression analysis of the factors associated with renal impairment. As such, the observed factors may not be independently associated with renal impairment since potential confounders/covariates were not controlled for statistically in the analysis.

\section{ABBREVIATION:}

AIDS: Acquired Immune Deficiency Syndrome;

ARV: anti-retroviral drug;

ART: highly active antiretroviral therapy;

BMI: body mass index;

$\mathrm{CrCl}$ : creatinine clearance;

HIV: Human Immunodeficiency Virus;

NNRTI:non-nucleoside reverse transcriptase inhibitor;

NtRTI: nucleotide reverse transcriptase inhibitor;

TDF: tenofovir disoproxil fumarate;

WHO: World HealthOrganisation.

PI: protease inhibitor

\section{REFERENCES:}

1. Estrella M, Moosa M, Nachega J. Risk and benefits of tenofovir in the context of kidney dysfunction in sub-Sarahan Africa. CID. 2014;58(10):1481-3.

2. Gallant JE, Staszewski S, Pozniak AL, DeJesus E, Suleiman JM, Miller MD, et al. Efficacy and safety of tenofovir DF vs stavudine in combination therapy in antiretroviral-naive patients: a 3-year randomized trial. JAMA. 2004;292:191-201.

3. Horberg M, Tang B, Towner W, Silverberg M, Bersoff-Matcha S, Hurley L, et al. Impact of tenofovir on renal function in HIV-infected, antiretroviral naive patients. J Acquir Immune Defic Syndr. 2010;53:62-9.

4. Calza L, Trapani F, Tedeschi S, Piergentili B, Manfredi R, Colangeli V, et al. Tenofovirinduced renal toxicity in $324 \mathrm{HIV-infected,} \mathrm{antiretroviral-naïve} \mathrm{patients.} \mathrm{Scand} \mathrm{J} \mathrm{Infect}$ induced renal toxicity
Dis. 2011;43:656-60.

5. Chua AC, Llorin RM, Lai K, Cavailler P, Law HL. Renal safety of tenofovir containing antiretroviral regimen in a Singapore cohort. AIDS Res Ther. 2012;9:19.

6. De Beaudrap P, Diallo MB, Landman R, Gueye NF, Ndiaye I, Diouf A, et al. Changes in the renal function after tenofovir-containing antiretroviral therapy initiation in a Senegalese cohort (ANRS 1215). AIDS Res Hum Retroviruses. 2010;26:1221-7.
7. Nishijima T, Komatsu H, Gatanaga H, Aoki T, Watanabe K, Kinai E, et al. Impact of small body weight on tenofovir-associated renal dysfunction in HIV-infected patients: a retrospective cohort study of Japanese patients. PLoS ONE. 2011;6:e22661.

8. Cooper RD, Wiebe N, Smith N, Keiser P, Naicker S, Tonelli M. Systematic review and meta-analysis: renal safety of tenofovir disoproxil fumarate in HIV-infected patients. Clin Infect Dis. 2010;51:496-505.

9. Madeddu G, Bonfanti P, De Socio GV, Carradori S, Grosso C, Marconi P, et al. Tenofovir renal safety in HIV-infected patients: results from the SCOLTA Project. Biomed Pharmacother. 2008;62:6-11.

10. Goicoechea M, Liu S, Best B, Sun S, Jain S, Kemper C, et al. Greater tenofovirassociated renal function decline with protease inhibitor-based versus nonnucleoside reverse-transcriptase inhibitor-based therapy. J Infect Dis. 2008;197:102-8.

11. Quesada PR, Esteban LL, Garcia JR, Sanchez RV, Garcia TM, Alonso-Vega GG, et al. Incidence and risk factors for tenofovir-associated renal toxicity in HIV-infected patients. Int J Clin Pharm. 2015;37:865-72.

12. Kamkuemah M, Kaplan R, Bekker LG, Little F, Myer L. Renal impairment in HIVinfected patients initiating tenofovir-containing antiretroviral therapy regimens in a Primary Healthcare Setting in South Africa. Trop Med Int Health. 2015;20:518-26. 